\title{
Uteroglobin, a Possible Ligand of the Lipoxin Receptor Inhibits Serum Amyloid A-Driven Inflammation
}

\author{
Giovanni Antico, ${ }^{1}$ Monica Aloman, ${ }^{2}$ Katja Lakota, ${ }^{3}$ Lucio Miele, ${ }^{4}$ \\ Stefano Fiore, ${ }^{5}$ and Snezna Sodin-Semrl ${ }^{3,6}$ \\ ${ }^{1}$ Astellas Pharma US, Northbrook, IL 60062, USA \\ ${ }^{2}$ Advocate Christ Medical Center \& Hope Children's Hospital, 4440 W 95th Street Oak Lawn, IL 60453, USA \\ ${ }^{3}$ Department of Rheumatology, University Medical Center-Ljubljana, 1000 Ljubljana, Slovenia \\ ${ }^{4}$ Departments of Medicine, Pharmacology, Biochemistry and Radiation Oncology, The University of Mississippi Medical Center, \\ Cancer Institute, Jackson, MS 39216, USA \\ ${ }^{5}$ Sanofi-Aventis, Bridgewater Township, NJ 08807, USA \\ ${ }^{6}$ Faculty of Mathematics, Natural Science and Information Technology, University of Primorska, 6000 Koper, Slovenia
}

Correspondence should be addressed to Snezna Sodin-Semrl; ssodin1@yahoo.com

Received 20 November 2013; Revised 31 January 2014; Accepted 7 February 2014; Published 23 March 2014

Academic Editor: Sunil Kumar Manna

Copyright (C) 2014 Giovanni Antico et al. This is an open access article distributed under the Creative Commons Attribution License, which permits unrestricted use, distribution, and reproduction in any medium, provided the original work is properly cited.

Serum amyloid A (SAA) production is increased by inflamed arthritic synovial tissue, where it acts as a cytokine/chemoattractant for inflammatory and immune cells and as an inducer of matrix degrading enzymes. SAA has been shown to bind lipoxin $\mathrm{A}_{4}$ receptor, a member of the formyl-peptide related 2 G-protein coupled receptor family (ALX) and elicit proinflammatory activities in human primary fibroblast-like synoviocytes (FLS). We report on the identification of uteroglobin, a small globular protein with potent anti-inflammatory activities, as a possible ligand of ALX. Uteroglobin-specific association with ALX was demonstrated by an enzyme immunoassay experiment employing a cell line engineered to express the human ALX receptor. Uteroglobin's interaction with ALX resulted in the inhibition of SAA responses, such as attenuation of phospholipase $\mathrm{A}_{2}$ activation and cellular chemotaxis. In FLS, uteroglobin showed an antagonism against SAA-induced interleukin-8 release and decreased cell migration. These novel roles described for uteroglobin via ALX may help elucidate genetic and clinical observations indicating that a polymorphism in the uteroglobin promoter is linked to disease outcome, specifically prediction of bone erosion in patients with rheumatoid arthritis or severity of IgA glomerulonephritis and sarcoidosis.

\section{Introduction}

Serum amyloid A (SAA) is an acute phase protein and inflammatory marker of rheumatoid arthritis (RA) and its disease progression [1]. During the acute phase response, SAA levels can increase up to 1000 -fold in the circulation of humans, making it a major acute phase reactant (APR) [2]. SAA promotes the release of cytokines and chemokines in fibroblast-like synoviocytes (FLS) by binding to its receptors, such as receptor for advanced glycation end-products [3] or through lipoxin $\mathrm{A}_{4}$ receptor (ALX), also called formylpeptide related 2 receptor [4].
ALX was originally reported to be present in FLS by our group in 2000 [5]. It is a member of the seven transmembrane G-protein coupled receptor family with different classes of ligands. Proinflammatory activation of cells expressing ALX was shown with bacterial and viral peptides, endogenous acute phase molecules, such as SAA, and the fibrinolytic receptor for urokinase [6-9]. An anti-inflammatory cascade of events was initially reported to be triggered by lipid ligands, such as endogenous arachidonate-derived lipoxygenase product lipoxin $\mathrm{A}_{4}\left(\mathrm{LXA}_{4}\right)$ [10-12], $\mathrm{LXA}_{4}$-derived

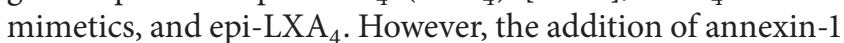
(a glucocorticoid-induced anti-inflammatory protein) to the 
growing family of ALX ligands has provided evidence that this receptor can also modulate anti-inflammatory signaling [13] via proteins.

Uteroglobin (UG), a steroid-inducible, $16 \mathrm{kDa}$ secreted protein with potent anti-inflammatory/immunomodulatory activities, was found to share short peptide sequence similarities with annexin-1, termed the antiflammin motif [14-17]. Endogenous nonapeptides or antiflammins were reported to carry regulatory effects on inflammation and overlapping biological activities [18-21]. UG and its peptide derivatives, the antiflammins, have also been reported to modulate effects on phospholipase $\mathrm{A}_{2}\left(\mathrm{PLA}_{2}\right)$ activity, phagocyte activation, formyl-methionyl-leucyl-phenylalanine (fMLP)- and complement fragment C5-induced chemotaxis, and phagocytosis of monocytes and neutrophils [22-25]. In contrast data has been reported on the ability of antiflammins to inhibit $\mathrm{PLA}_{2}$ activity $[14,19,26,27]$. Even though the basic nonapeptide antiflammin-2 was demonstrated to be devoid of PLA2 inhibitory activity [28], Kamal et al. reported on its selective binding to human ALX, thus providing a potential mechanism for its anti-inflammatory properties [29].

Like annexin-1, UG is also known as a secretory, glucocorticoid-inducible protein [17], while displaying powerful immunomodulatory properties, similar to those of $\mathrm{LXA}_{4}$, such as inhibition of IL-6 release [30], reduction of cellular infiltrates in the airways [31], decreased synthesis of prostaglandins (namely, $\mathrm{PGF}_{2}$ and $\mathrm{PGE}_{2}[32]$ ), and reduced lysophosphatidic acid plasma levels [33].

The ability of UG to limit the availability of intracellular arachidonate (by strongly inhibiting phospholipase $\mathrm{A}_{2}$ activity) and prevent the generation of lipid mediators has been proposed as the main mechanism leading to its antiinflammatory activity $[14,15]$. This has led us to investigate whether UG can also interact and signal via ALX, as well as elicit similar anti-inflammatory functions.

The current report indicates that UG interacts with ALX and, similarly to $\mathrm{LXA}_{4}$ and/or annexin-1, activates a potent negative feedback mechanism on cellular inflammatory events. We show that several previously reported UG biological responses could be based on its molecular interaction with ALX.

\section{Materials and Methods}

2.1. Ethics Statement. This study was performed in accordance with US guidelines and was approved by the Internal Review Board at the University of Illinois at Chicago, where the study was conducted.

2.2. Cell Cultures. Human primary synovial fibroblasts (FLS) obtained from arthroscopic knee biopsies were cultured in EMEM supplemented with $10 \%$ fetal bovine serum (FBS). Fresh medium containing 5\% FBS was added to cell culture 24 hours prior to each experiment. FLS passages 7-11 were used.

The promyelocytic leukemia cell line (HL-60) was grown [34] in RPMI 1640 containing 10\% FBS. HL-60 cells stably transfected with either empty pcDNA-3 (HL60 ${ }^{\text {pcDNA3 }}$ ) or
pcDNA-3 containing the ALX open reading frame (HL60 ALX $)$ were cultured in presence of $400 \mu \mathrm{g} / \mathrm{mL}$ of $\mathrm{G} 418$.

Chinese hamster ovary (CHO) cells were cultured in $\alpha$-MEM supplemented with adenosine, deoxyadenosine, thymidine $(0.2 \mathrm{mg} / \mathrm{mL}$ each), and $10 \%$ FBS. CHO cells stably transfected with either empty pINF plasmid $\left(\mathrm{CHO}^{\mathrm{pINF}}\right)$ or pINF containing the ALX open reading frame $\left(\mathrm{CHO}^{\mathrm{ALX}}\right)$ were selected in presence of $5 \mu \mathrm{g} / \mathrm{mL}$ of puromycin.

Human endometrial cells-1A (HEC-1A) and HEC-1A UG were kindly provided by Dr. Peri A. (Department of Clinical Physiopathology, University of Florence, Italy) and grown in McCoys medium, supplemented with $10 \%$ FBS and sodium bicarbonate $(2.2 \mathrm{~g} / \mathrm{L})$. G418 was used as selective antibiotic for HEC-1A ${ }^{\mathrm{UG}}$. Human recombinant UG (hrUG) was kindly provided by Claragen Inc. (Rockville, MD, USA). Human recombinant SAA1/2 (hrSAA) was purchased from Peprotech (Rocky Hill, NJ, USA).

\subsection{RNA Isolation and Reverse Transcription-PCR. Total} RNA was extracted with TRIZOL Reagent (Life Technologies, Rockville, MD). RNA reverse transcription (RT) system was used according to the manufacturer's instructions (Promega, Madison, WI, USA) and RT-PCR was performed as follows: for UG, forward primer (within exon 1): $5^{\prime}$-CTC ACC CTG GTC ACA CTG G-3'; reverse primer (within exon 3): $5^{\prime}$ TTG AAG AGA GCA AGG CTG GT-3' at an annealing temperature of $50^{\circ} \mathrm{C}$ with 30 cycle amplification in order to obtain a 344 bp fragment. Nested reverse transcription-PCR was required for detection of UG in FLS, with the forward primer as stated above and the reverse primer (within exon 2): $5^{\prime}$-GGG TGT CCA CCA GCT TCT TC- $3^{\prime}$ at an annealing temperature of $47^{\circ} \mathrm{C}$ with 30 cycle amplification to obtain a fragment of $180 \mathrm{bp}$ in size. ALX analysis was conducted as previously published [5].

2.4. Antisense Oligonucleotides. Phosphorothioate oligos were purchased from IDT (Coralville, IA, USA). For ALX, previously published antisense and sense oligonucleotides were used [12]. For UG, the antisense oligo was $5^{\prime}-C^{*} T^{*} G^{*}$ AAA AGT TCC ATG GC ${ }^{*} \mathrm{~A}^{*} \mathrm{G}^{*}-3^{\prime}$ and the scrambled oligo was: $5^{\prime}-\mathrm{C}^{*} \mathrm{C}^{*} \mathrm{G}^{*}$ TGC TGT ACC TAG $\mathrm{TG}^{*} \mathrm{~A}^{*} \mathrm{G}^{*}-3^{\prime} \quad$ (* indicate phosphorothioate bonds). Oligos were added to cell culture supernatants at a final concentration of $8 \mu \mathrm{g} / \mathrm{mL}$ for $48 \mathrm{~h}$ and readministered a second time for another $72 \mathrm{~h}$ prior to treatments.

2.5. Modified Enzyme Immunoassay (EIA). CHO cells were cultured in 96-well plates up to $80 \%$ of confluency. The cells were then washed three times with PBS prior incubation with increasing concentrations of UG diluted in $\alpha$-MEM $(200 \mu \mathrm{L} /$ well $)$ for $10 \mathrm{~min}$ at $4^{\circ} \mathrm{C}$. After washing with PBS, the cells were incubated for $1 \mathrm{~h}$ at room temperature with goat anti-UG antibody $(20 \mu \mathrm{g} / \mathrm{mL})$ diluted in a solution containing $\mathrm{CHO}^{\text {pINF }}$ culture supernatant and fresh $\alpha$-MEM $(5 \% \mathrm{v} / \mathrm{v})$. The cells were then washed twice with PBS and incubated for $45 \mathrm{~min}$ at room temperature with 1:2000 dilution of horseradish peroxidase-conjugated anti-goat antibody (Vector laboratories, Burlingame, CA). Contribution 


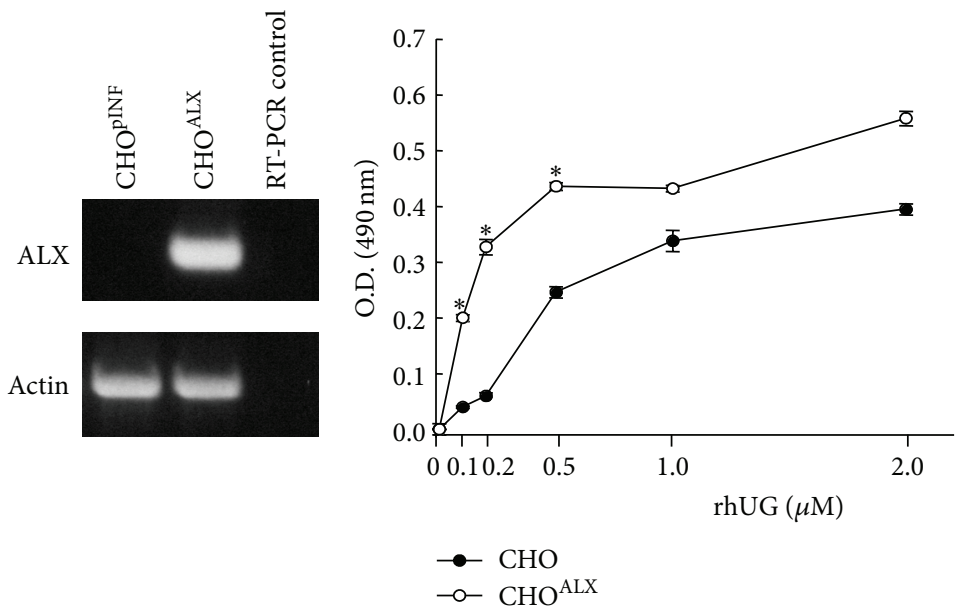

FIGURE 1: Exogenous hrUG binding by CHO cells expressing ALX shown by modified enzyme immunoassay. CHO cells expressing either the empty vector pcDNA3 vector $\left(\mathrm{CHO}^{\mathrm{PINF}}\right)$ or containing the full ALX open reading frame $\left(\mathrm{CHO}^{\mathrm{ALX}}\right)$ were exposed to increasing hrUG concentrations. The asterix notation indicates data points with a $P$ value of $<0.02$ when comparing $\mathrm{CHO}^{\mathrm{ALX}}$ to $\mathrm{CHO}^{\mathrm{pINF}}$ data series. Results are plotted as a mean \pm SD of quadruplicate determinations performed in three separate experiments. Reverse transcription-PCR was used to monitor the ALX mRNA expression in CHO cells stably transfected with ALX cDNA (inset). Control represents no template added to reaction. ALX is lipoxin $\mathrm{A}_{4}$ receptor or FPR2/ALX. The result is from a representative gel of two performed.

of endoperoxidase was abolished by cell treatment with $0.01 \%$ hydrogen peroxide for $30 \mathrm{sec}$. After two washings with PBS, the cells were incubated at room temperature with o-phenylenediamine dihydrochloride solution in citrate buffer (Pierce Biotechnology, Rockford, IL) containing 0.03\% hydrogen peroxide. The colorimetric reaction was stopped using $2 \mathrm{~N}$ sulfuric acid. Supernatants $(200 \mu \mathrm{L})$ from each well were transferred to a 96-well plate and color intensity measured at $490 \mathrm{~nm}$. The values were normalized by protein content. Cells used in the assay were fixed in $10 \%$ trichloroacetate solution $\left(1 \mathrm{~h}\right.$ at $\left.20^{\circ} \mathrm{C}\right)$. After drying, the content of each well was stained with $1 \%$ sulforhodamine B (Sigma, St. Louis, MO), washed in acetic acid and resuspended in 50\% Tris base solution, followed by detection at $510 \mathrm{~nm}$.

2.6. Phospholipase $A_{2}\left(P L A_{2}\right)$ Assay. Phospholipase activity was measured by determining the release of the free acid form of tritiated arachidonic acid after esterification of the labeled arachidonate to membrane phospholipids [35]. Values for tritiated AA release recovered in the supernatant were determined by $\gamma$-scintillation counting at indicated time points.

2.7. Interleukin-8 Release. ELISA was used to measure released IL-8 levels in culture supernatants as previously reported [5] and following manufacturer's instructions (Invitrogen, USA).

2.8. Chemotaxis Assays. The chemotaxis assays were performed as previously described $[8,16]$. Briefly, HL- $60^{\text {pcDNA3 }}$ and HL- $60^{\mathrm{ALX}}$ were cultured overnight in RPMI containing $0.1 \%$ FBS and then seeded onto $8 \mu \mathrm{m}$ pore polycarbonate membrane transwells. SAA and UG were added to the lower chambers of the transwells at indicated concentrations. After
$1 \mathrm{~h}$ incubation at $37^{\circ} \mathrm{C}$, suspensions in the lower chambers were collected. Subsequently, the cells were treated with propidium iodide and analyzed for number and morphology by FACS.

Human FLS were plated to confluency onto transwells with $8 \mu \mathrm{m}$ pore polycarbonate inserts using either PC-1 or phenol red-free DMEM. After $12 \mathrm{~h}$ in serum-free conditions, chemotaxis was assessed for $2 \mathrm{~h}$ after addition of agonists into the lower chamber. Migrated cells were manually counted (Crystal Violet staining) or measured by metabolic colorimetric assay (formazan, EZ4U, ALPCO Diagnostics, Windham, NH, USA).

2.9. Statistical Analysis. All experiments were repeated at least three times (unless otherwise noted) and the mRNA results by RT-PCR were shown as a representative gel of two performed. Data are reported as mean \pm SD. Means were compared between treated and control groups with Student's $t$-test and significant $P$ values less than 0.05 determined to be statistically significant.

\section{Results}

3.1. Characterization of UG Interactions with $A L X$. In order to determine whether UG can bind to ALX, we first used an adherent cell line Chinese hamster ovary cells ( $\mathrm{CHO})$, stably transfected with mock pINF vector as well as overexpressing the human ALX in a modified enzyme immunoassay (EIA). A higher and specific UG binding was observed in $\mathrm{CHO}^{\mathrm{ALX}}$ cells as compared to mock $\mathrm{CHO}^{\text {pINF }}$ (Figure 1) with ALX mRNA expression only in the $\mathrm{CHO}^{\mathrm{ALX}}$ transfected cells (Figure 1 inset).

The protein-receptor assays on the cells were performed at $4^{\circ} \mathrm{C}$, since the interaction itself could be modified by 


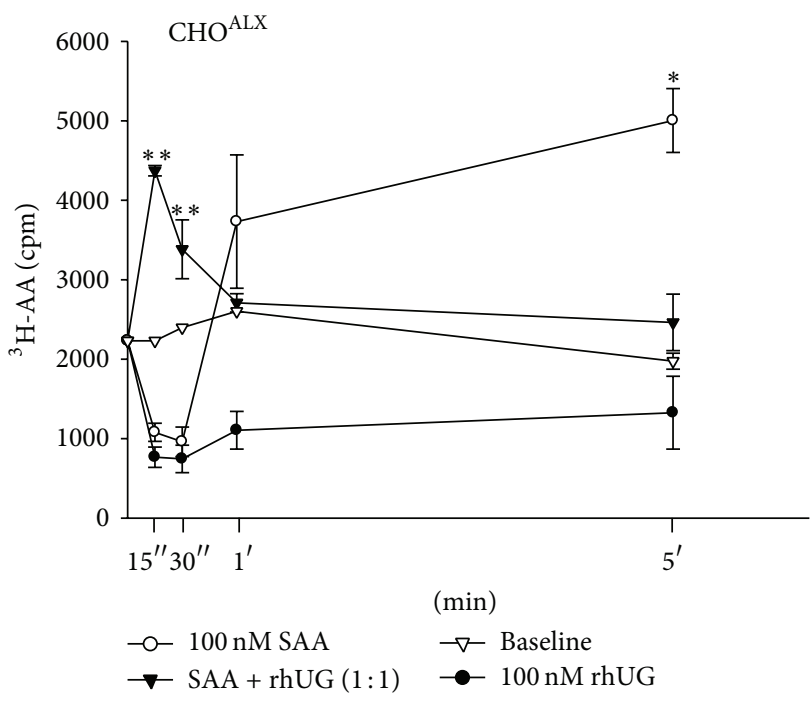

(a)

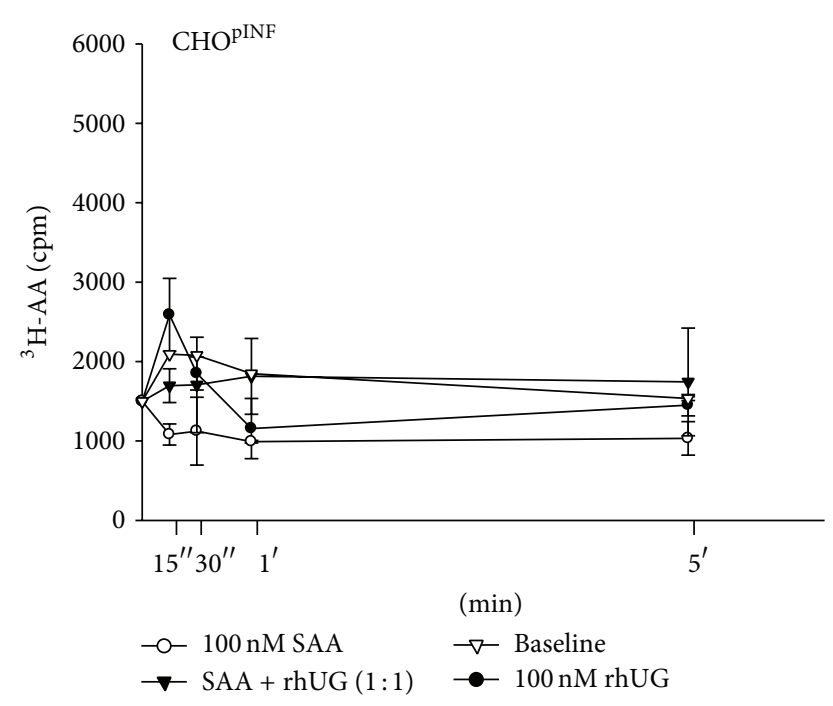

(b)

FIGURE 2: SAA-induced phospholipase $\mathrm{A}_{2}$ activity is attenuated by UG in CHO cells overexpressing ALX. Time response of SAA-induced $\mathrm{PLA}_{2}$ activity in $\mathrm{CHO}^{\mathrm{ALX}}$ cells (a) over a 5-minute monitoring period in the presence and absence of UG, as compared to mock transfected CHO cells (b). Significance is noted by Student's $t$-test of SAA treatment versus SAA + UG treatment. $*$ for $P<0.005$ and $* *$ for $P<0.001$. Results represent the mean $\pm \mathrm{SD}$ of four separate experiments with triplicate determinations.

cell activities, such as internalization of the protein/receptor complex, expulsion, or masking by intervening membrane events.

Since the UG-dependent dose curve in $\mathrm{CHO}^{\mathrm{pINF}}$ indicates the existence of other proteins/receptors dependent on UG in these cells, such as fibronectin [36], we cannot exclude that further effects of UG go through alternative pathways.

3.2. Human Recombinant UG Modulates SAA-Induced ALXDependent Cell Signaling. UG ability to modulate ALX signaling was determined in $\mathrm{CHO}$ cells by comparing the effects of UG and SAA, alone or in combination, on $\mathrm{PLA}_{2}$ activity (Figure 2). SAA upregulated $\mathrm{PLA}_{2}$ activation selectively in cells overexpressing ALX $\left(\mathrm{CHO}^{\mathrm{ALX}}\right.$, Figure 2(a)), while no response was obtained in control cells $\left(\mathrm{CHO}^{\mathrm{pINF}}\right.$, Figure 2(b)). This is in striking contrast to UG effects resulting in a selective downmodulation of basal levels of $\mathrm{PLA}_{2}$ activity (Figure 2(a)). Interestingly, results indicate that UG triggers an early peak of transient activity in the presence of SAA in $\mathrm{CHO}^{\mathrm{ALX}}$. This early $\mathrm{PLA}_{2}$ activity peak is followed by a sustained inhibition of SAA-induced activation at later time points (Figure 2(a)). There is also a transient early peak of UG in mock transfected CHO cells (Figure 2(b)), which is lower than the early combined effect of SAA and UG in $\mathrm{CHO}^{\mathrm{ALX}}$.

3.3. Functional Consequence of UG on SAA-Induced Release of IL-8 and Cellular Chemotaxis in Human Cell Lines and Primary Synovial Fibroblasts. Since endogenous synthesis of UG could contribute potential confounding elements, HEC$1 \mathrm{~A}$ cells, which naturally do not express the UG gene, were used in comparison with HEC-1A engineered to overexpress $\mathrm{UG}\left(\mathrm{HEC}-1 \mathrm{~A}^{\mathrm{UG}}\right.$ ). Additionally an antisense oligo (AS-ALX) treatment was established to modulate the receptor expression in HEC-1A (Figure 3(a)). As shown in Figure 3(b), left side of the graph, wild type HEC-1A cells lacking synthesis of endogenous UG, responded to SAA with a fivefold increase in synthesis of IL- 8 over the control, and yet released IL-8 levels were reduced to background level, when cell expression of ALX had been silenced by treating cells with AS-ALX. In HEC-1A ${ }^{\mathrm{UG}}$ cells with endogenous UG synthesis, SAAinduced IL-8 released levels were also decreased (Figure 3(b), right side of the graph). UG secretion alone also decreased the baseline value of released IL- 8 levels. The overall conclusion is that the SAA effect on IL-8 is still seen with UG present; however, is significantly attenuated.

Chemotaxis is the primary consequence of the release of IL-8. Therefore, we determined the impact of UG on SAAinduced chemotaxis in both HL-60 cells and FLS. FLS are known to possess SAA-dependent ALX-mediated responses, including chemotaxis [7]. SAA had a dose-dependent effect on cell chemotaxis in HL-60 ${ }^{\text {ALX }}$ (black bars) but not in mock transfected cells (white bars, Figure 4(a)). Its potency was compared to that observed with 5\% FBS, a standard stimulus used to provoke chemotaxis via multiple, nonreceptorrestricted mechanisms, and also able to mobilize mock HL-60 cells (Figure 4). Besides the increase of chemotactic response caused by SAA, expression levels of ALX and endogenous UG were also found to correlate with the number of cells undergoing chemotaxis (Figure 4(b)). More specifically, baseline values in control samples more than doubled when comparing mock with HL-60 ${ }^{\text {ALX }}$ cells and they increased even further if endogenous UG synthesis was silenced (Figure 4(b) and inset).

The effects of SAA and UG on cellular chemotaxis were confirmed using human primary FLS, where only traces of 


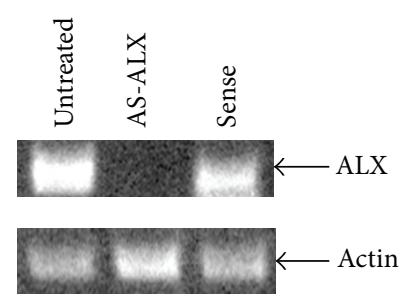

(a)

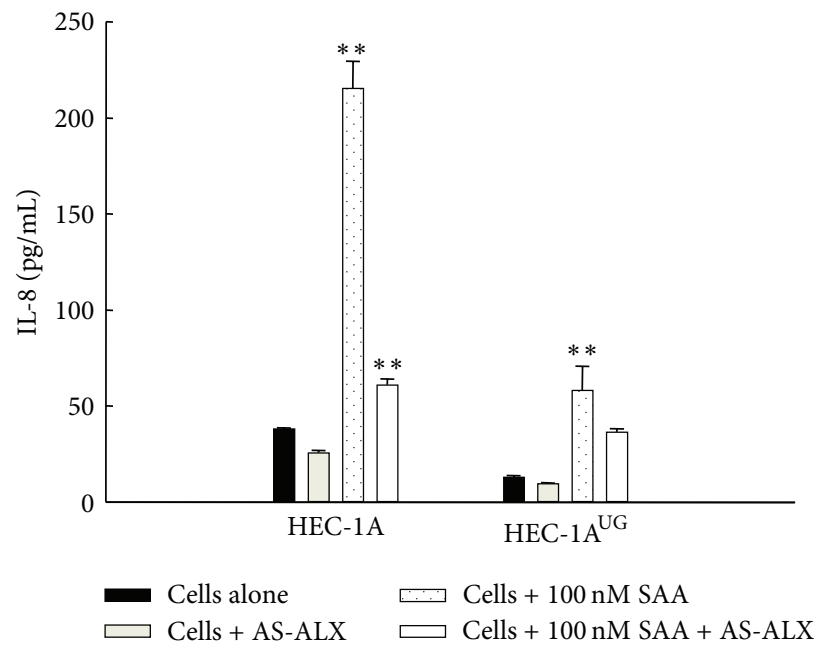

(b)

FIGURE 3: SAA-induced IL-8 levels were significantly downregulated in HEC-1A cells overexpressing UG. (a) Reverse transcription-PCR of ALX mRNA in HEC-1A cells and ALX-antisense (AS-ALX) oligo-treated HEC-1A cells. The result is from a representative gel of two performed. (b) SAA-dependent IL-8 release as measured by ELISA, in HEC-1A cells, is inhibited when pretreated with ALX-antisense oligo. In HEC-1 $\mathrm{A}^{\mathrm{UG}}$ cells SAA-induced IL-8 release is significantly lower in comparison to HEC-1A. Student's $t$-test for SAA versus AS-ALX treated HEC-1A cells or HEC-1A ${ }^{\text {UG }}$ cells was calculated, $P<0.0001(* *)$. Data were normalized using number of cells. Results are the mean \pm SD of three separate experiments with quadruplicate determinations.

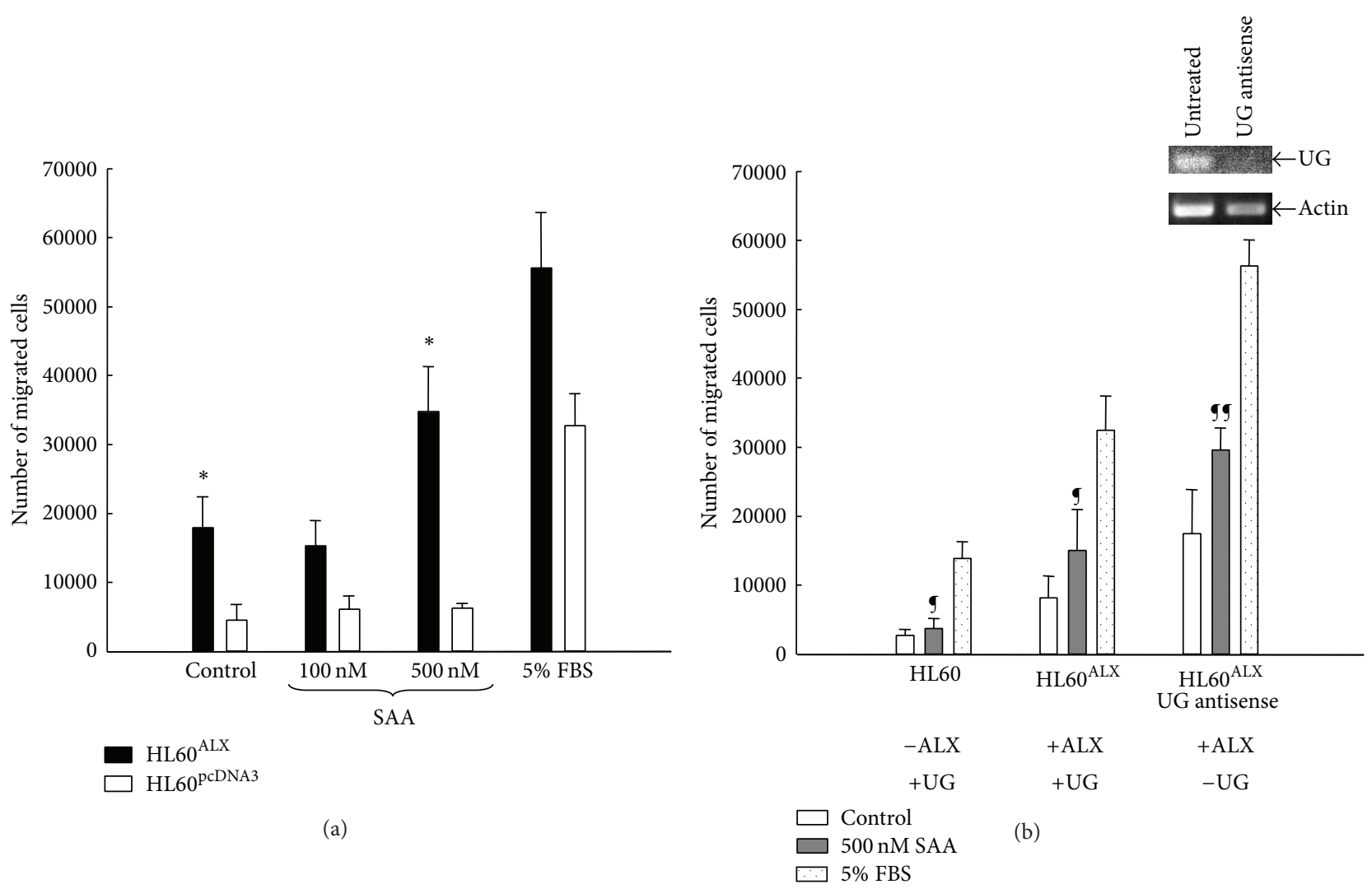

FIGURE 4: SAA-stimulated migration of HL-60 is mediated by ALX while being inhibited by UG. (a) Migration of HL60 ${ }^{\text {ALX }}$ and HL60 into the lower chamber when SAA at two different concentrations (100 and $500 \mathrm{nM}$ ) or 5\% FBS (positive control) are added. (b) Migration of HL60, HL60 ${ }^{\mathrm{ALX}}$, and UG-antisense treated HL60 cells when SAA $(500 \mathrm{nM})$ or $5 \%$ FBS were added. Results are the mean \pm SD of four separate experiments with triplicate determinations. 
decameric and higher molecular weight complexes of UG were visible as detected by western blots (slightly above the test detection limits of $\sim 2 \mathrm{ng}$ protein $/ 3 \times 10^{6}$ cells, data not shown). These UG amounts (calculated at $\sim 12 \mathrm{pM}$ ) are negligible since they would represent concentrations of three $\log$ orders lower than the estimated affinity for ALX and $\sim 1,000$-fold less than that achieved with exogenously added UG (100 nM and Figure 1). Results in Figure 5 indicate that SAA-induced chemotaxis in human FLS is strongly inhibited by equimolar concentrations of UG, while UG alone had no effect on the number of migrated cells in control samples. In parallel experiments SAA caused a distinct elevation of IL- 8 and determined a selective accumulation in the lower chamber compartment, while UG counteracted these effects (Figure 5(b)). Results also indicate that the SAA-induced IL-8 gradient is functionally relevant since its disruption with IL-8 blocking sera causes a significant reduction in the number of cells migrating from the upper to the lower compartment of the transwell (Figure 5(c)).

\section{Discussion}

Investigations with UG-knockout mice revealed that the absence of this protein can lead to phenotypes that suggest its critical homeostatic role/s in inflammation, autoimmunity, cancer, and other processes [37].

UG interactions with ALX seem to be linked to antiinflammatory/proresolution events. While a growing number of ALX agonists have been reported, the characterization of their signaling pathways remains incomplete. In 2006, Kamal et al. reported that antiflammin-2 bound ALX, elicited postreceptor signaling responses, such as rapid phosphorylation of ERK1 and ERK2, and provided functional data in terms of inhibiting PMN interaction with endothelial monolayer under flow [29].

We report for the first time that UG could bind to ALX and through this receptor elicits inhibition of SAAinduced cellular PLA2 activity. UG binding to ALX yields a tonic inhibition of basal $\mathrm{PLA}_{2}$ activity levels. When being in combination with SAA, a rapid and pulsed PLA ${ }_{2}$ activation was observed, followed by inhibition of SAA activity. In fact, the $\mathrm{PLA}_{2}$ activation profile observed with SAA is typically observed with GPCRs activated by proinflammatory mediators such as FMLP or leukotriene $\mathrm{B}_{4}[38,39]$. UG pulsed $\mathrm{PLA}_{2}$ activation overlaps with the $\mathrm{LXA}_{4}$ profile that is accompanied by an extensive membrane lipid remodeling without the full activation of proinflammatory events, such as synthesis of proinflammatory eicosanoids from the unesterified AA $[10,12,35]$. Furthermore, the time profile of UG inhibition of SAA-induced PLA 2 activity and the use of low concentrations of divalent cations in the assay $\left(\mathrm{Ca}^{2+}\right.$ plus $\mathrm{Mg}^{2+}<0.8 \mathrm{mM}$ ) strongly suggest that these events involve intracellular $\mathrm{PLA}_{2}$ isoforms, expanding on the UG repertoire of anti-inflammatory actions in addition to the inhibition of the secretory form of PLA ${ }_{2}$, as initially reported when UG properties were originally described [14].
Notably, further evidence of receptor antagonism between UG and SAA was obtained by measuring SAA-induced IL-8 release. The ALX role in UG and SAA signaling was established by suppressing its expression with ALX antisense oligo. The characterization of UG impact on this event was conducted using a HEC-1A, cell line devoid of endogenous UG synthesis, and stably transfected cells HEC-1A ${ }^{\mathrm{UG}}$. Levels of IL-8 released after SAA challenge were found to be higher in HEC-1A than HEC-1 $\mathrm{A}^{\mathrm{UG}}$ and were affected by ALX antisense treatment. Notably, also the basal levels of IL-8 production were higher in wild type HEC-1A than in UG producing HEC-1A, suggesting that the autocrine action of UG is critical to both antagonizing SAA-induced, ALXmediated release of IL-8, and regulating IL-8 basal levels. The role of endogenously synthesized UG on regulating basal level of IL-8 production overlaps with the inhibition of p38 phosphorylation basal levels and suggests that endogenous UG may be pivotal to "prevent" the ALX contribution to proinflammatory networks by opposing its association with proinflammatory ligands.

Ray et al. [40] reported that allergen exposure induces elevated expression of serum amyloid $\mathrm{A}$ in the lungs of UG knock-out mice. SAA higher production was found to provide a chemotactic signal for the migration of dendritic cells and UG was shown to inhibit SAA-induced migration of mL4-7 cells. These cells were generated by stably transfecting HEC-293 cells with FPR2 (a mouse homolog of the human FPRL1/ALX receptor) cDNA construct in a dosedependent manner. In the current report, we also found that UG counteracts SAA-induced cell migration (as shown on nonadherent HL-60 cells in an ALX-dependent manner, as well as of adherent primary human FLS).

We have indication that UG synthesis occurs in a myeloid related cell lineage (data not shown). Our results indicate binding of $\alpha \mathrm{UG}$ to HL- $60^{\mathrm{ALX}}$ with no further binding noted with the addition of exogenous UG. HL-60 cells were chosen for our studies since SAA-induced chemotaxis in myeloid cells and its dependence on ALX have been already established [6]. Our results obtained with HL-60 cells confirm that SAA is able to promote cell chemotaxis if cells are transfected with ALX. With use of UG antisense oligo to abolish endogenous UG synthesis, results indicate that loss of UG synthesis is accompanied by an exacerbated HL-60 cell chemotactic response to SAA. This suggested that, as proposed for IL-8 release in HEC-1A, endogenously synthesized UG exerts a tonic inhibition on activation of cell responses triggered by proinflammatory mediators.

While the use of engineered cell lines allowed for the intended characterization of UG interactions with ALX and resulting biological responses, FLS were used to evaluate the pathophysiological relevance of these events specifically in human synovium of arthritic joints. Moreover, the ability of cells to migrate upon SAA chemoattraction has been reported [6] so impact of UG on this chemotaxis was tested. UG was found to be a potent inhibitor of SAA-induced FLS chemotaxis and the inhibition was accompanied by a striking reduction in IL-8 levels. In fact, IL-8 measurements in the upper and lower chambers of the transwell system 


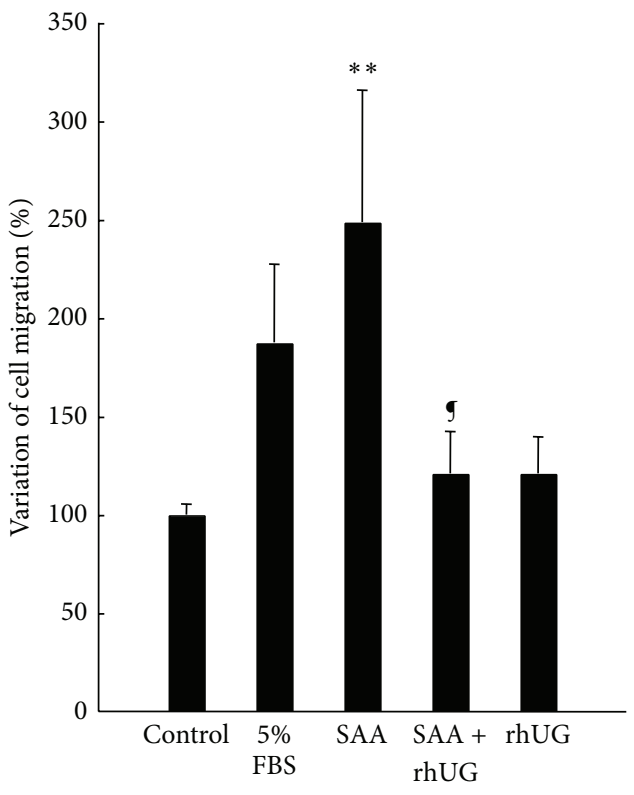

(a)

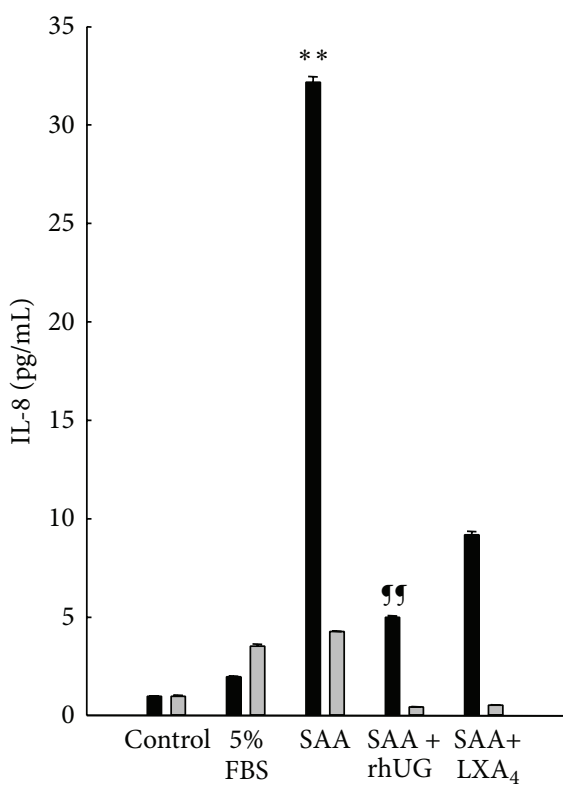

(b)

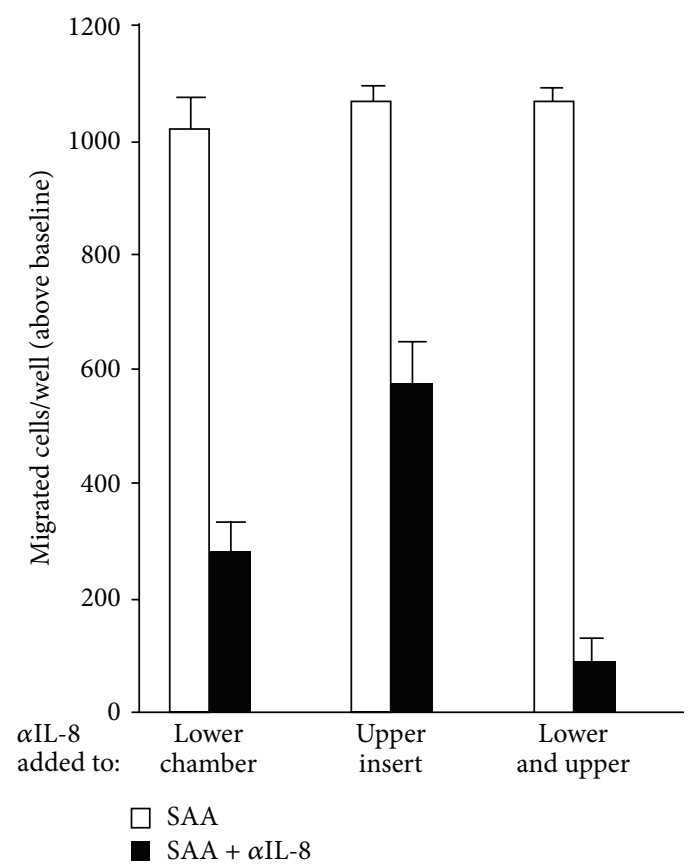

(c)

FIGURE 5: Attenuation of SAA induced cell migration and released IL- 8 by hrUG in FLS. (a) Migration of FLS exposed to FBS, SAA (100 nM), or SAA with UG $(100 \mathrm{nM})$, shown as \% variation above control (basal growth medium). Results are the mean \pm SD of three separate experiments with duplicate determinations. (b) Released IL-8 levels as measured by ELISA in the lower and upper chamber medium following FLS treatment with $5 \%$ FBS, SAA $(100 \mathrm{nM})$ alone or in combination with UG or LXA 4 (both at $100 \mathrm{nM})$. Results are the mean \pm SD of duplicate determinations from two experiments. Data are normalized using cell numbers. (c) Migration of FLS following SAA (100 nM) treatment in lower chambers when IL-8 blocking antibody was added to lower, upper, or both compartments of the transwell system. Student's $t$-test SAA versus control $P$ values of $<0.005(* *)$ and SAA versus SAA + UG treatments $P$ values of $<0.01(\mathbf{g})$ (a) and $<0.002(\mathbf{g g})$ (b). Results are the mean \pm SD from quadruple determinations of two experiments performed. 
adopted for these experiments suggest that SAA, but not FBS, establishes a clear chemotactic gradient that is opposed by the presence of equimolar amounts of UG.

Taken together, there is a possibility that UG acts through pathways other than ALX. With the experiments performed we cannot rule out that fibronectin or other receptors might bind UG as well and trigger pathways, creating cross-talk signaling with ALX.

A single nucleotide polymorphism in the UG gene (A587G) appears to be associated with low risk of erosive disease in rheumatoid arthritis patients [41]. This indicates that UG could play a protective role in chronic inflammatory joint diseases. UG could be an attractive therapeutical option in the future, as reviewed by Pilon [42]. Evidence to this effect is coming from various fields of study. Mice lacking UG are highly susceptible to pulmonary fibrosis and recombinant UG was shown to prevent bleomycin-induced production of proinflammatory T-helper 2 cytokines and TGF- $\beta$, which are profibrotic. So, UG seems to be critical in preventing pulmonary fibrosis in mice [43]. Also, humans characterized to be deficient in UG exhibited tendencies toward inflammatory, fibrotic, and oncologic diseases [42]. UG was indicated to be likely to have a role as a lung surfactant-protective agent, especially important in neonatal respiratory distress syndrome. Human recombinant UG was tested in one of the first clinical trials for its effectiveness in protecting the surfactant, a complex mixture of phospholipids and proteins, from degradation by PLA2 catalysis and was shown to be safe when administered endotracheally [37]. UG was also discovered to prevent IgA mediated diseases, such as IgA nephropathy, by preventing the deposition of IgA-fibronectin immunocomplexes in tissues, such as the renal glomeruli [44].

In conclusion, identification of possible ALX-mediated UG activities extends the characterization of the antiinflammatory properties previously described for UG. Our results indicate that UG can potently impact positive feedback mechanisms (IL-8 release) involved in SAA proinflammatory cell activation. UG may play a preeminent role in modulating inflammatory events across various target tissues. Its interaction with ALX, expressed on phagocytic cells, such as macrophages and PMN, as well as the currently documented ability of UG endogenous synthesis in cells of myeloid lineage, extends the pathophysiological relevance of UG anti-inflammatory activities beyond organs, such as lung and endometrium, where abundant presence of the protein and anti-inflammatory activities had been previously acknowledged [16, 45, 46].

\section{Abbreviations}

ALX: $\quad$ Lipoxin $\mathrm{A}_{4}$ receptor

AP1: $\quad$ Activating protein 1

CHO: Chinese hamster ovary cells

FI: $\quad$ Fluorescence intensity

FLS: $\quad$ Fibroblast like synoviocytes

HEC-1A: Human endometrium cell line $1 \mathrm{~A}$

HL-60: Human promyelocytic cell line 60

IL-1 $\beta$ : Interleukin 1 beta

$\begin{array}{ll}\text { IL-8: } & \text { Interleukin } 8 \\ \text { LXA }_{4}: & \text { Lipoxin } \mathrm{A}_{4} \\ \text { NF-kB: } & \text { Nuclear factor kappa B } \\ \text { PLA }_{2}: & \text { Phospholipase } \mathrm{A}_{2} \\ \text { SAA (rhSAA1): } & \text { Serum amyloid A } \\ \text { UG (rhUG): } & \begin{array}{l}\text { Recombinant human uteroglobin, } \\ \text { also known as CC10 protein. }\end{array}\end{array}$

\section{Conflict of Interests}

The authors declared that they have no conflict of interests regarding the publication of this paper.

\section{Acknowledgments}

The authors express their deep gratitude to Dr. Aprile Pilon, Claragen Inc. (Rockville, MD), for providing rhUG and $\alpha$ UG Abs and to Dr. Alessandro Peri, Department of Clinical Physiopathology, University of Florence, Florence, Italy, for providing Human endometrial cells-1A (HEC-1A) and HEC$1 \mathrm{~A}^{\mathrm{UG}}$. This work was supported by grants from NIH (no. AR45931 to Stefano Fiore) and the Arthritis Foundation, Greater Chicago Chapter (to Snezna Sodin-Semrl). Contributions of all authors to the paper have preceded their employment in current institutions/companies.

\section{References}

[1] G. Cunnane, S. Grehan, S. Geoghegan et al., "Serum amyloid A in the assessment of early inflammatory arthritis," Journal of Rheumatology, vol. 27, no. 1, pp. 58-63, 2000.

[2] C. Gabay and I. Kushner, "Acute-phase proteins and other systemic responses to inflammation," The New England Journal of Medicine, vol. 340, no. 6, pp. 448-454, 1999.

[3] H. Okamoto, Y. Katagiri, A. Kiire, S. Momohara, and N. Kamatani, "Serum amyloid A activates nuclear factor- $\kappa \mathrm{B}$ in rheumatoid synovial fibroblasts through binding to receptor of advanced glycation end-products," Journal of Rheumatology, vol. 35, no. 5, pp. 752-756, 2008.

[4] S. Sodin-Semrl, A. Spagnolo, R. Mikus, B. Barbaro, J. Varga, and S. Fiore, "Opposing regulation of interleukin- 8 and NF-kB responses by lipoxin A4 and serum amyloid a via the common lipoxin a receptor," International Journal of Immunopathology and Pharmacology, vol. 17, no. 2, pp. 145-156, 2004.

[5] S. Sodin-Semrl, B. Taddeo, D. Tseng, J. Varga, and S. Fiore, "Lipoxin A4 inhibits IL- $1 \beta$-induced IL-6, IL-8, and matrix metalloproteinase-3 production in human synovial fibroblasts and enhances synthesis of tissue inhibitors of metalloproteinases," Journal of Immunology, vol. 164, no. 5, pp. 2660-2666, 2000.

[6] S. B. Su, W. Gong, J.-L. Gao et al., "A seven-transmembrane, $\mathrm{G}$ protein-coupled receptor, FPRL1, mediates the chemotactic activity of serum amyloid A for human phagocytic cells," Journal of Experimental Medicine, vol. 189, no. 2, pp. 395-402, 1999.

[7] R. Badolato, J. M. Wang, W. J. Murphy et al., "Serum amyloid $\mathrm{A}$ is a chemoattractant: induction of migration, adhesion, and tissue infiltration of monocytes and polymorphonuclear leukocytes," Journal of Experimental Medicine, vol. 180, no. 1, pp. 203-209, 1994. 
[8] M. Resnati, I. Pallavicini, J. M. Wang et al., "The fibrinolytic receptor for urokinase activates the $\mathrm{G}$ protein-coupled chemotactic receptor FPRL1/LXA4R," Proceedings of the National Academy of Sciences of the United States of America, vol. 99, no. 3, pp. 1359-1364, 2002.

[9] Y. Le, P. M. Murphy, and J. M. Wang, "Formyl-peptide receptors revisited," Trends in Immunology, vol. 23, no. 11, pp. 541-548, 2002.

[10] S. Fiore, J. F. Maddox, H. D. Perez, and C. N. Serhan, "Identification of a human CDNA encoding a functional high affinity lipoxin A4 receptor," Journal of Experimental Medicine, vol. 180, no. 1, pp. 253-260, 1994.

[11] T. Takano, S. Fiore, J. F. Maddox, H. R. Brady, N. A. Petasis, and C. N. Serhan, "Aspirin-triggered 15-epi-lipoxin A4 (LXA4) and LXA4 stable analogues are potent inhibitors of acute inflammation: evidence for anti-inflammatory receptors," Journal of Experimental Medicine, vol. 185, no. 9, pp. 1693-1704, 1997.

[12] S. Fiore and C. N. Serhan, "Lipoxin A4 receptor activation is distinct from that of the formyl peptide receptor in myeloid cells: inhibition of CD11/18 expression by lipoxin A4-lipoxin A4 receptor interaction," Biochemistry, vol. 34, no. 51, pp. 1667816686, 1995.

[13] M. Perretti, N. Chiang, M. La et al., "Endogenous lipid- and peptide-derived anti-inflammatory pathways generated with glucocorticoid and aspirin treatment activate the lipoxin A4 receptor," Nature Medicine, vol. 8, no. 11, pp. 1296-1302, 2002.

[14] L. Miele, E. Cordella-Miele, A. Facchiano, and A. B. Mukherjee, "Inhibition of phospholipase A2 by uteroglobin and antiflammin peptides," Advances in Experimental Medicine and Biology, vol. 279, pp. 137-160, 1990.

[15] L. Miele, E. Cordella-Miele, and A. B. Mukherjee, "Uteroglobin: structure, molecular biology, and new perspectives on its function as a phospholipase A2 inhibitor," Endocrine Reviews, vol. 8, no. 4, pp. 474-490, 1987.

[16] A. B. Mukherjee, E. Cordella-Miele, T. Kikukawa, and L. Miele, "Modulation of cellular response to antigens by uteroglobin and transglutaminase," Advances in Experimental Medicine and Biology, vol. 231, pp. 135-152, 1988.

[17] L. Miele, E. Cordella-Miele, A. Facchiano, and A. B. Mukherjee, "Novel anti-inflammatory peptides from the region of highest similarity between uteroglobin and lipocortin I," Nature, vol. 335, no. 6192, pp. 726-730, 1988.

[18] L. Miele, "Bioactive peptides derived from uteroglobin," Annals of the New York Academy of Sciences, vol. 923, pp. 128-140, 2000.

[19] F. Marki, J. Pfeilschifter, H. Rink, and I. Wiesenberg, "'Antiflammins': two nonapeptide fragments of uteroglobin and lipocortin I have no phospholipase A2-inhibitory and anti-inflammatory activity," FEBS Letters, vol. 264, no. 2, pp. 171-175, 1990.

[20] J. J. Moreno, "Antiflammins: endogenous nonpeptides with regulatory effect on inflammation," General Pharmacology, vol. 28, no. 1, pp. 23-26, 1997.

[21] J. J. Moreno, "Antiflammin peptides in the regulation of inflammatory response," Annals of the New York Academy of Sciences, vol. 923, pp. 147-153, 2000.

[22] G. Vasanthakumar, R. Manjunath, A. B. Mukherjee, H. Warabi, and E. Schiffmann, "Inhibition of phagocyte chemotaxis by uteroglobin, an inhibitor of blastocyst rejection," Biochemical Pharmacology, vol. 37, no. 3, pp. 389-394, 1988.

[23] I. Dierynck, A. Bernard, H. Roels, and M. De Ley, “The human Clara cell protein: biochemical and biological characterisation of a natural immunosuppressor," Multiple Sclerosis, vol. 1, no. 6, pp. 385-387, 1996.
[24] G. Camussi, C. Tetta, F. Bussolino, and C. Baglioni, "Antiinflammatory peptides (antiflammins) inhibit synthesis of plateletactivating factor, neutrophil aggregation and chemotaxis, and intradermal inflammatory reactions," Journal of Experimental Medicine, vol. 171, no. 3, pp. 913-927, 1990.

[25] E. Schiffmann, V. Geetha, D. Pencev et al., "Adherence and regulation of leukotaxis," Agents and Actions, vol. 12, pp. 106120, 1983.

[26] A. Facchiano, E. Cordella-Miele, L. Miele, and A. B. Mukherjee, "Inhibition of pancreatic phospholipase A2 activity by uteroglobin and antiflammin peptides: possible mechanism of action," Life Sciences, vol. 48, no. 5, pp. 453-464, 1991.

[27] J. J. Moreno, "Effects of antiflammins on transglutaminase and phospholipase A2 activation by transglutaminase," International Immunopharmacology, vol. 6, no. 2, pp. 300-303, 2006.

[28] W. C. Hope, B. J. Patel, and D. R. Rolin, "Antiflammin-2 (HDMNKVLDL) does not inhibit phospholipase A2 activities," Agents and Actions, vol. 34, no. 1-2, pp. 77-80, 1991.

[29] A. M. Kamal, R. P. G. Hayhoe, A. Paramasivam et al., "Antiflammin-2 activates the human formyl-peptide receptor like 1," TheScientificWorldJournal, vol. 6, pp. 1375-1384, 2006.

[30] G. W. Mango, C. J. Johnston, S. D. Reynolds, J. N. Finkelstein, C. G. Plopper, and B. R. Stripp, "Clara cell secretory protein deficiency increases oxidant stress response in conducting airways," The American Journal of Physiology: Lung Cellular and Molecular Physiology, vol. 275, no. 2, pp. L348-L356, 1998.

[31] K. S. Harrod, A. D. Mounday, B. R. Stripp, and J. A. Whitsett, "Clara cell secretory protein decreases lung inflammation after acute virus infection," The American Journal of Physiology: Lung Cellular and Molecular Physiology, vol. 275, no. 5, pp. L924L930, 1998.

[32] T. Kikukawa, B. D. Cowan, R. I. Tejada, and A. B. Mukherjee, "Partial characterization of a uteroglobin-like protein in the human uterus and its temporal relationship to prostaglandin levels in this organ," Journal of Clinical Endocrinology and Metabolism, vol. 67, no. 2, pp. 315-321, 1988.

[33] A. B. Mukherjee, G. C. Kundu, A. K. Mandal, N. Pattabiraman, C.-J. Yuan, and Z. Zhang, "Uteroglobin: physiological role in normal glomerular function uncovered by targeted disruption of the uteroglobin gene in mice," The American Journal of Kidney Diseases, vol. 32, no. 6, pp. 1106-1120, 1998.

[34] S. Fiore, M. Romano, E. M. Reardon, and C. N. Serhan, "Induction of functional lipoxin A4 receptors in HL-60 cells," Blood, vol. 81, no. 12, pp. 3395-3403, 1993.

[35] S. Nigam, S. Fiore, F. W. Luscinskas, and C. N. Serhan, "Lipoxin A4 and lipoxin B4 stimulate the release but not the oxygenation of arachidonic acid in human neutrophils: dissociation between lipid remodeling and adhesion," Journal of Cellular Physiology, vol. 143, no. 3, pp. 512-523, 1990.

[36] G. Antico, M. W. Lingen, A. Sassano et al., "Recombinant human uteroglobin/CC10 inhibits the adhesion and migration of primary human endothelial cells via specific and saturable binding to fibronectin," Journal of Cellular Physiology, vol. 207, no. 2, pp. 553-561, 2006.

[37] A. B. Mukherjee, Z. Zhang, and B. S. Chilton, "Uteroglobin: a steroid-inducible immunomodulatory protein that founded the Secretoglobin superfamily," Endocrine Reviews, vol. 28, no. 7, pp. 707-725, 2007.

[38] S. Reddy, R. Bose, G. H. Rao, and M. Murthy, "Phospholipase A2 activation in human neutrophils requires influx of extracellular $\mathrm{Ca}^{2+}$ and leukotriene B4," The American Journal of Physiology: Cell Physiology, vol. 268, no. 1, pp. C138-C146, 1995. 
[39] C. N. Serhan, M. J. Broekman, and H. M. Korchak, "Endogenous phospholipid metabolism in stimulated neutrophils: differential activation by FMLP and PMA," Biochemical and Biophysical Research Communications, vol. 107, no. 3, pp. 951958, 1982.

[40] R. Ray, Z. Zhang, Y.-C. Lee, J.-L. Gao, and A. B. Mukherjee, "Uteroglobin suppresses allergen-induced $\mathrm{TH} 2$ differentiation by down-regulating the expression of serum amyloid $\mathrm{A}$ and SOCS-3 genes," FEBS Letters, vol. 580, no. 25, pp. 6022-6026, 2006.

[41] J. J. Goronzy, E. L. Matteson, J. W. Fulbright et al., "Prognostic markers of radiographic progression in early rheumatoid arthritis," Arthritis and Rheumatism, vol. 50, no. 1, pp. 43-54, 2004.

[42] A. L. Pilon, "Rationale for the development of recombinant human $\mathrm{CC10}$, as a therapeutic for inflammatory and fibrotic disease," Annals of the New York Academy of Sciences, vol. 923, pp. 280-299, 2000.

[43] Y.-C. Lee, Z. Zhang, and A. B. Mukherjee, "Mice lacking uteroglobin are highly susceptible to developing pulmonary fibrosis," FEBS Letters, vol. 580, no. 18, pp. 4515-4520, 2006.

[44] A. B. Mukherjee, F. Zheng, and Z. Zhang, "Uteroglobin in the treatment of IgA mediated disease," United States Patent US 8, 084, 415 B2, 2011.

[45] A. Peri, E. Cordella-Miele, L. Miele, and A. B. Mukherjee, "Tissue-specific expression of the gene coding for human Clara cell $10-\mathrm{kD}$ protein, a phospholipase A2-inhibitory protein," Journal of Clinical Investigation, vol. 92, no. 5, pp. 2099-2109, 1993.

[46] A. Peri, B. D. Cowan, D. Bhartiya et al., "Expression of Clara cell $10-\mathrm{kD}$ gene in the human endometrium and its relationship to ovarian menstrual cycle," DNA and Cell Biology, vol. 13, no. 5, pp. 495-503, 1994. 


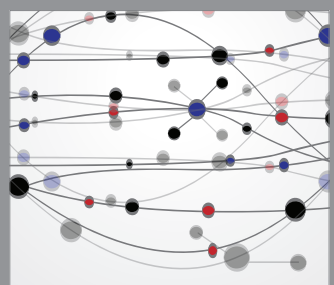

The Scientific World Journal
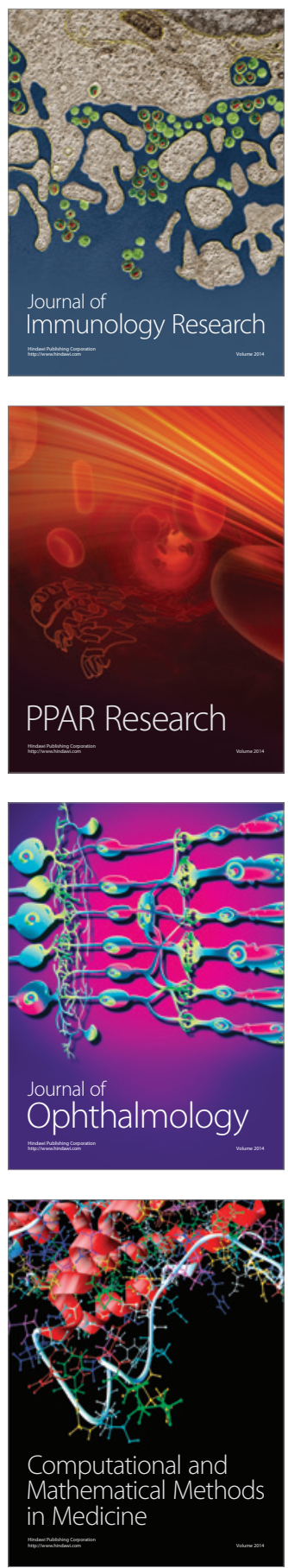

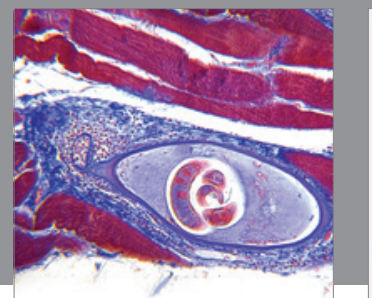

Gastroenterology

Research and Practice
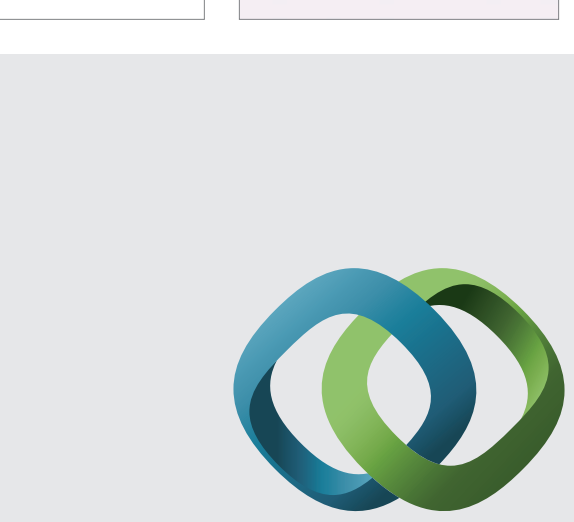

\section{Hindawi}

Submit your manuscripts at

http://www.hindawi.com
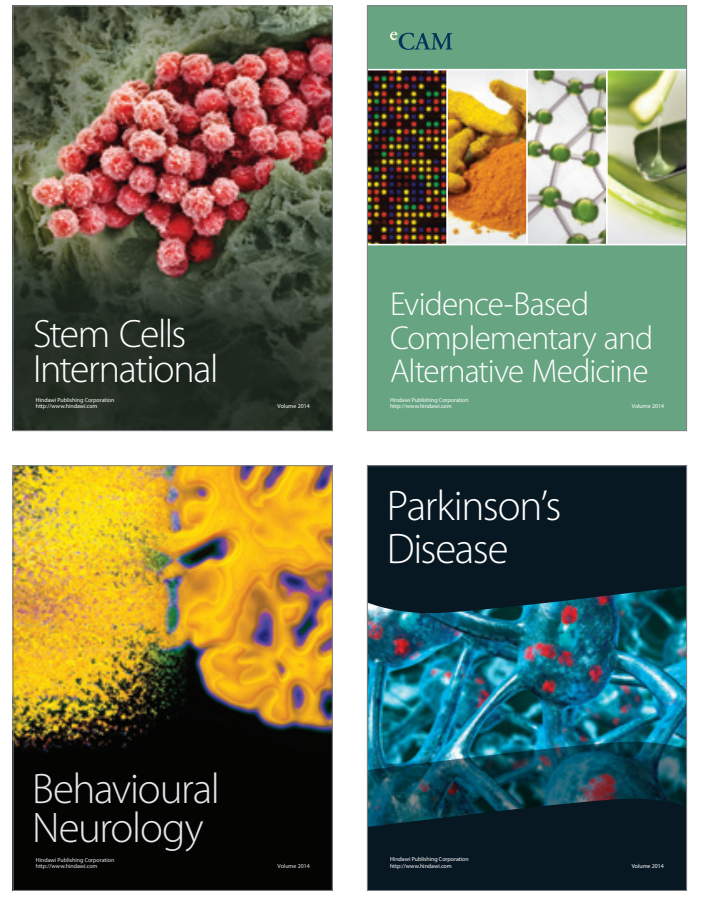
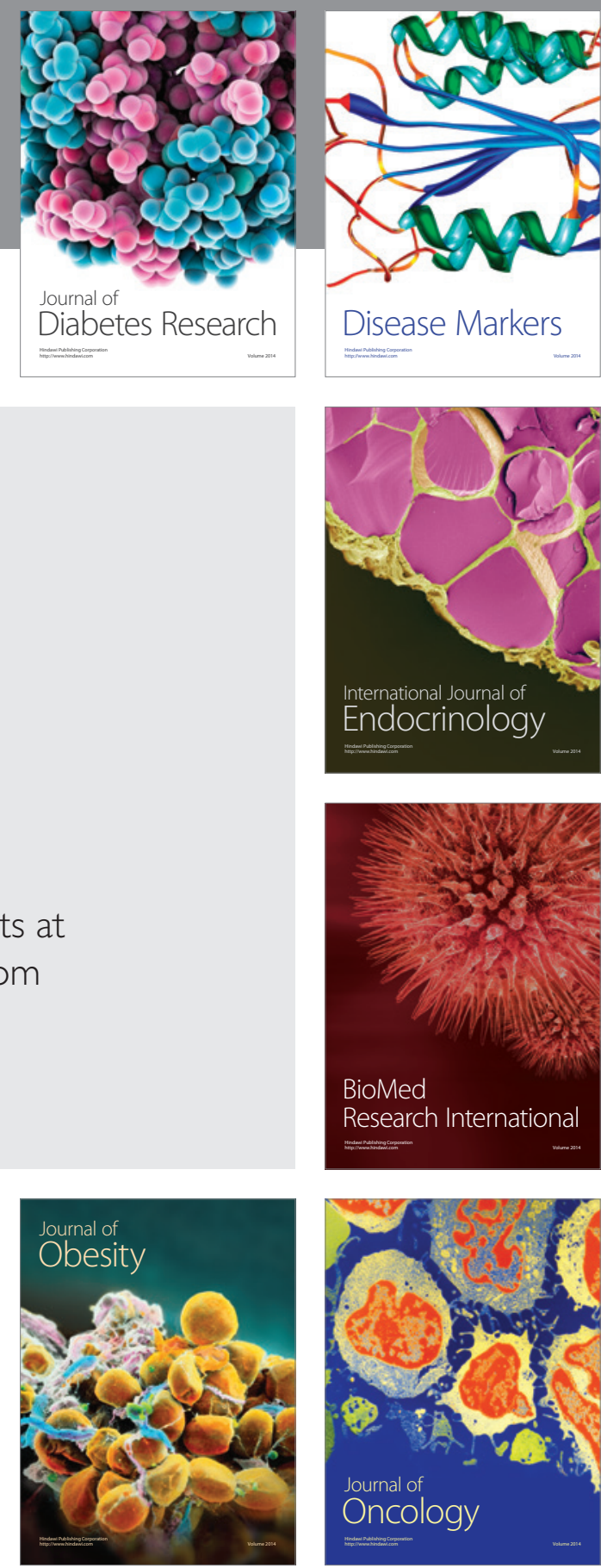

Disease Markers
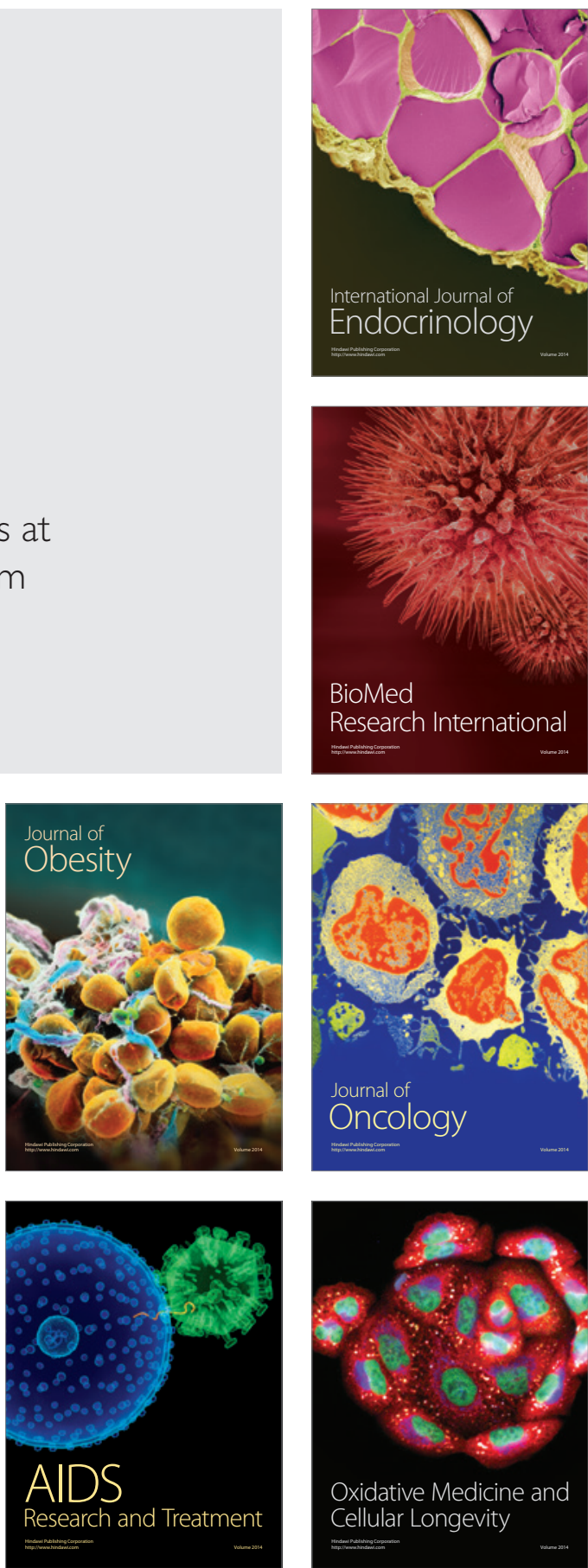